This item was submitted to Loughborough's Research Repository by the author.

Items in Figshare are protected by copyright, with all rights reserved, unless otherwise indicated.

\title{
Lessons learned about the diagnosis of pathologies in concrete dams: 30 years of research and practice
}

PLEASE CITE THE PUBLISHED VERSION

https://doi.org/10.1016/j.conbuildmat.2018.11.143

PUBLISHER

(C) Elsevier

VERSION

AM (Accepted Manuscript)

\section{PUBLISHER STATEMENT}

This paper was published in the journal Construction and Building Materials and the definitive published version is available at https://doi.org/10.1016/j.conbuildmat.2018.11.143.

\section{LICENCE}

CC BY-NC-ND 4.0

\section{REPOSITORY RECORD}

Blanco-Alvarez, Ana, F. Pardo-Bosch, Sergio Pialarissi-Cavalaro, and Antonio Aguado. 2019. "Lessons Learned About the Diagnosis of Pathologies in Concrete Dams: 30 Years of Research and Practice". figshare. https://hdl.handle.net/2134/36306. 


\title{
Lessons learned on the diagnosis of pathologies in concrete dams: 30 years of research and practice
}

\author{
A. Blanco ${ }^{1}$, F. Pardo-Bosch ${ }^{2}$, S. Cavalaro ${ }^{1}$, A. Aguado $^{3}$ \\ ${ }^{1}$ Loughborough University, School of Architecture, Building and Civil Engineering, Epinal Way, LE11 3TU, \\ Loughborough, United Kingdom \\ 2Universitat Ramon Llull, ESADE Business School, Av. Pedralbes 60-62, 08034 Barcelona, Spain \\ ${ }^{3}$ Universitat Politècnica de Catalunya, Dept. of Civil and Environmental Engineering, Jordi Girona 1-3, 08034 \\ Barcelona, Spain.
}

\section{Summary}

Studies on the diagnosis of pathologies of concrete dams are a valuable reference for professionals managing such assets. However, detailed information is rarely reported in the literature. This paper compiles the most important lessons learned during 30 years of practical experience on this area. The diagnostic procedure is illustrated through 4 of the most interesting dams analysed and monitored by the authors. All were subjected to a first stage that included inspection and analysis of historical documentation, leading to the proposal of a diagnose hypothesis. This was followed by a second stage that included an experimental programme with laboratory tests and, in some cases, numerical simulations to confirm or reject the hypothesis. The analysis of the information shows different pathologies and provide a wide spectrum of boundary conditions, symptoms and diagnoses (from internal sulphate attack and alkaliaggregate reaction to soil-structure interaction).

Keywords: dam, diagnosis, internal sulphate attack, alkali-aggregate reaction, delayed ettringite formation

\section{INTRODUCTION}

The construction of concrete dams generally implies the use of massive amounts of aggregates, cement and admixtures. The rule of thumb is to use aggregates quarried from nearby geologic formations to reduce costs and simplify the construction process. Despite the logistic and economic benefit, such an approach may lead to durability problems in case the quality of the aggregate is not verified in detail [1]. This is the case of many concrete dams built before the middle of the $20^{\text {th }}$ century when standard testing procedures and limitations for the composition and physical characteristics of the aggregates were not in place. Several dams from this period have experienced some sort of durability problem, displaying considerable displacements and/or cracking.

These symptoms have been widely attributed to expansive reactions and, with less frequency, to negative soil-structure interactions. The alkali-aggregate reaction (AAR) is recognized as the main cause of expansions of concrete dams. The internal sulphate attack (ISA) is another reaction identified in a smaller number of cases. Abundant studies from the literature addressed the chemical, the mechanical and structural aspects of these reactions [2-6]. However, limited information is available on the diagnostic procedure adopted to confirm the causes of the problem observed in the dams from a practical standpoint.

Based on almost 30 years of experience studying dams affected by durability issues, a common diagnostic procedure was developed. Experimental and numerical tools are used as a complementary way to reach a conclusive answer about the causes of the problems observed. The objective of this paper is to describe the steps of the diagnostic procedure proposed and successfully applied to dams with durability issues. Among nearly 15 dams inspected and monitored by the authors over the years, the 4 most interesting cases are outlined to illustrate the 
diagnostic procedure. This paper shows a wide spectrum of boundary conditions, symptoms and diagnoses that may become a reference for professionals in charge of assessing the state and managing concrete dams.

\section{DIAGNOSTIC PROCEDURE}

The diagnostic procedure of pathologies in dams is composed by a sequence of activities divided into two stages, with the activities and tasks summarized in Table 1. The first stage usually lasts a few weeks and involves damage detection, the study of the clinical history, field inspections, initial cabinet works and definition of the first hypothesis. The second stage entails laboratory tests, numerical modelling, validations of hypothesis and prediction of future behaviour. Given the magnitude of the activities in this stage, it may take from weeks to months to be completed. Additional information on the diagnostic procedure may be found in [7].

\begin{tabular}{|c|c|c|}
\hline Stage & Activities & Tasks \\
\hline \multirow{9}{*}{$\begin{array}{l}\text { First } \\
\text { stage }\end{array}$} & \multirow{2}{*}{ Clinical history } & Study of historical documents \\
\hline & & Analysis of monitoring data \\
\hline & \multirow{4}{*}{ Field (dam) inspection } & $\begin{array}{l}\text { Inspection of geological formation (abutments, original } \\
\text { quarry...) }\end{array}$ \\
\hline & & $\begin{array}{l}\text { Inspection of the dam: externally (crest of the dam, faces...) } \\
\text { and internally if possible (galleries) }\end{array}$ \\
\hline & & Mechanical / Moving elements (floodgates, safety railing...) \\
\hline & & Auxiliary / annex structures \\
\hline & \multirow[t]{2}{*}{ Initial cabinet works } & $\begin{array}{l}\text { Interpreting the monitoring data and associate it with } \\
\text { possible existing phenomena }\end{array}$ \\
\hline & & Identify the extent of the damage (global or localized) \\
\hline & First hypothesis & $\begin{array}{l}\text { Proposal for a plausible source of damage based on the } \\
\text { activities above }\end{array}$ \\
\hline \multirow{5}{*}{$\begin{array}{l}\text { Second } \\
\text { stage }\end{array}$} & \multirow{2}{*}{ Tests in the laboratory } & $\begin{array}{l}\text { Mechanical/physical tests in samples from the dam } \\
\text { (concrete and/or aggregate samples) }\end{array}$ \\
\hline & & $\begin{array}{l}\text { Microstructural analyses in samples from the dam (to detect } \\
\text { possible chemical reactions) }\end{array}$ \\
\hline & Numerical modelling & $\begin{array}{l}\text { Models are often used to predict future behaviour and in } \\
\text { some cases for the diagnosis }\end{array}$ \\
\hline & $\begin{array}{l}\text { Validation of the } \\
\text { hypothesis }\end{array}$ & Confront real data and behaviour with \\
\hline & $\begin{array}{l}\text { Prediction of future } \\
\text { behaviour }\end{array}$ & $\begin{array}{l}\text { Use the previous information to estimate the future } \\
\text { evolution of damage and its consequences }\end{array}$ \\
\hline
\end{tabular}

Table 1. Summary of the stages and tasks involved in the diagnostic procedure.

The analysis of clinical history is certainly valuable and can support the initial hypothesis. However, given the old age of some of the dams, in some cases part or all historical records are unavailable. Although the diagnostic procedure becomes more complex in this case, it is still possible to find the source of damage without monitoring data and historical records, as the authors have shown in [8]. In such situations, the field inspection becomes essential. Another paramount activity in the diagnosis is the execution of in-situ or laboratory tests whose results may support or reject the initial hypothesis. Numerical models are often used to predict the future behaviour of the dam. Nevertheless, in some cases, they may complement the experimental results in the validation of the hypothesis, as shown by $[9,10]$. 
The following sections describe four case studies chosen by the authors among the several concrete dams studied throughout the years. Each of them focuses on a different pathology or source of damage, thus providing a variety of examples that can serve as a valuable reference for future diagnosis.

\section{CASE STUDY I: CONCRETE DAM WITH ISA AND AAR}

\subsection{Characteristics of the dam and current state}

Case study I (Figure 1a) was selected due to the magnitude of the non-recoverable displacements and the singularity of the pathology - a combination of two expansive reactions with different kinetics. This concrete-made, gravity dam was built from 1968 to 1971 and presents a straight shape in the top view, with a crest length of $102.4 \mathrm{~m}$ and a height of $28.9 \mathrm{~m}$. The dam is divided into 1 block (number 1) that is $12.4 \mathrm{~m}$ wide and 6 blocks that are $15.0 \mathrm{~m}$ wide (numbers 2 to 7 ). The dam presents one gallery and the reservoir has a capacity of $0.33 \mathrm{hm}^{3}$. Slate and phyllites are the predominant surrounding geologic formation (Figure 1b), which is also the most likely source of the aggregates to produce the concrete used in the dam. This hypothesis was later confirmed by the historical construction records and by the microstructural analyses performed.
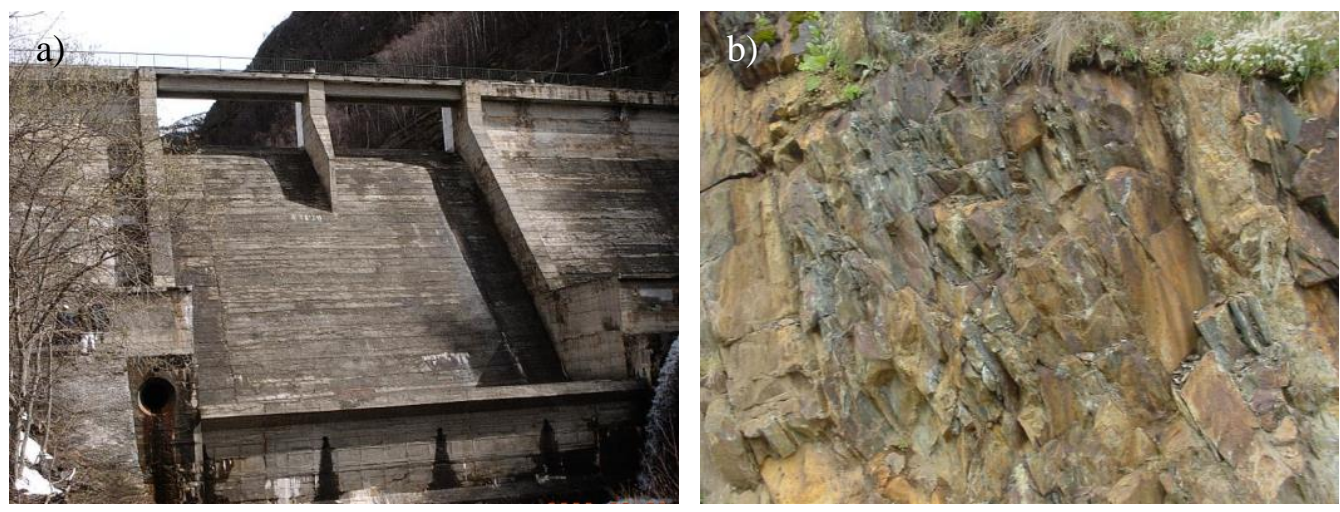

Figure 1. a) General view of the downstream face in 2005 and b) slates found near the dam.

Several visual inspections conducted over the years indicated signs of damage in the dam (both externally and internally in the gallery). Externally, map cracking was clearly visible in the downstream face of the dam, combined with deposition of ochre shading precipitates (see Figure 2a) most likely related to the oxidation of iron sulfides from the aggregates used in the concrete. The same was also detected in nearby auxiliary structures, such as shown in Figure $2 b$.
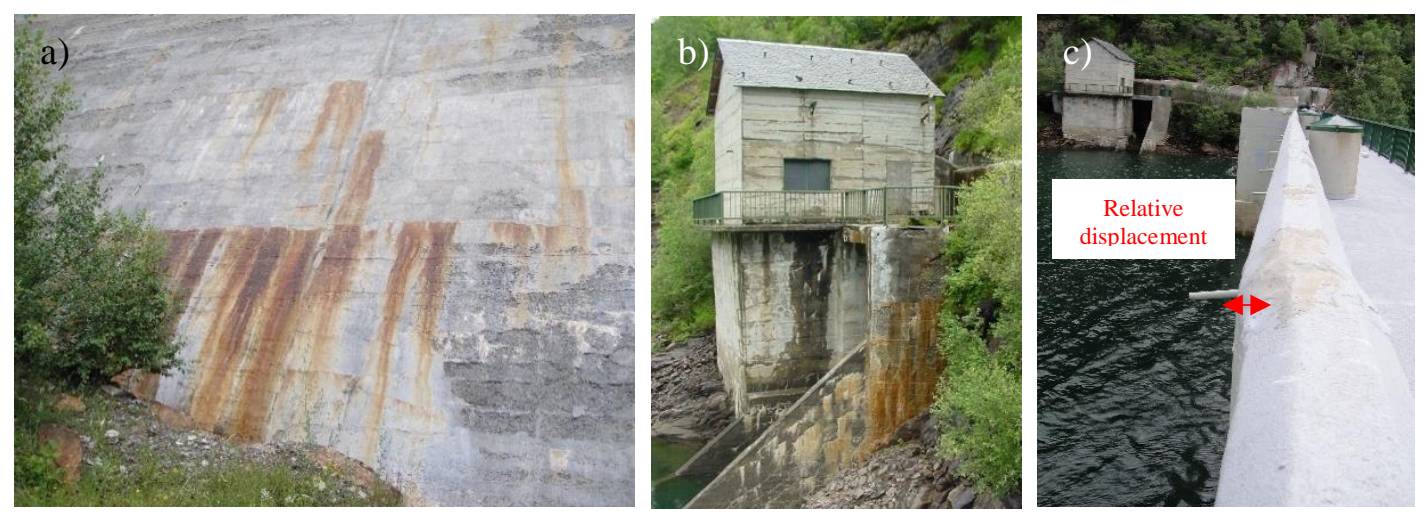
Figure 2. a) Map cracking in the downstream face and ochre shading precipitate found in 2011, b) same signs in auxiliary structure inspected in 2004 and c) relative displacement between blocks.

Additional evidence of a pathology was detected in the crest, where fixed elements such as the safety railing suggested relative displacements between the blocks. This is clearly visible in the picture taken in 2011 from the crest of the downstream face (Figure 2c) despite the maintenance operations performed in previous years. Periodical visits to the gallery of the dam allowed assessing the state of the concrete inside the dam, which also exhibited cracking and deposition ochre shading precipitates, as shown in Figure 3. Upon entering the gallery, a strong sulfur-like odour is perceptible - an evidence of the presence of sulphides precipitates in combination with a potential biologic action.

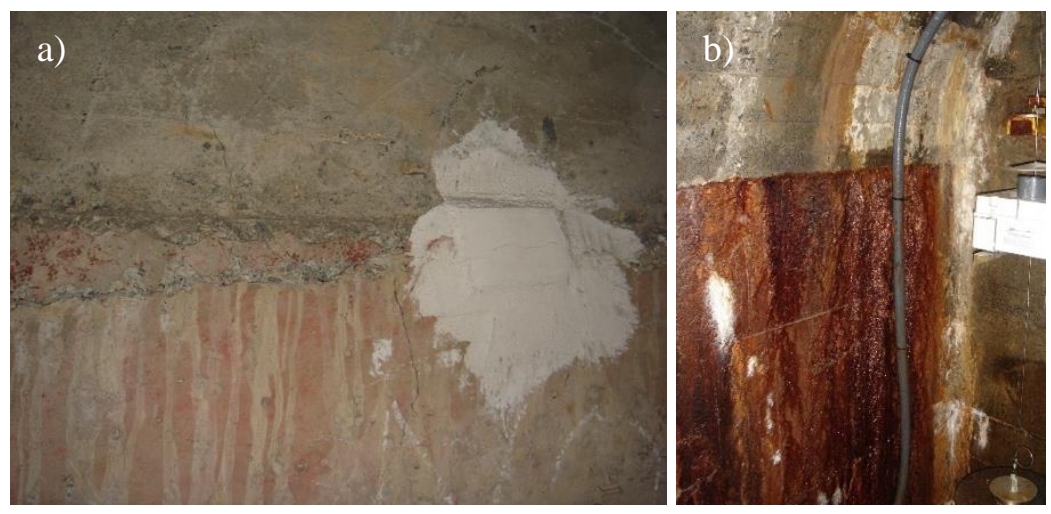

Figure 3. a) Cracking and b) ochre shading precipitate in the gallery.

Figure 4 shows the evolution of the vertical and the horizontal displacements at the crest of the dam since 1981 for Blocks 1 to 7. The curves reveal significant, non-recoverable displacements in both directions. Horizontal displacements towards the upstream direction are approximately 2 times bigger than the upward vertical displacements. Until 2015, the former reaches $249 \mathrm{~mm}$, whereas the latter approach $115 \mathrm{~mm}$ in blocks 4 and 5. Based on the authors' experience, such displacements are remarkably large for a dam with only $28.9 \mathrm{~m}$ of maximum height, equating to an average vertical strain of nearly $4 \%$. Notice that this strain is beyond the limit strain in compression typically allowed for concrete in structural design codes (e.g. Euro Code 2 that indicates 3.5\% for normal strength concrete in the ultimate limit state).
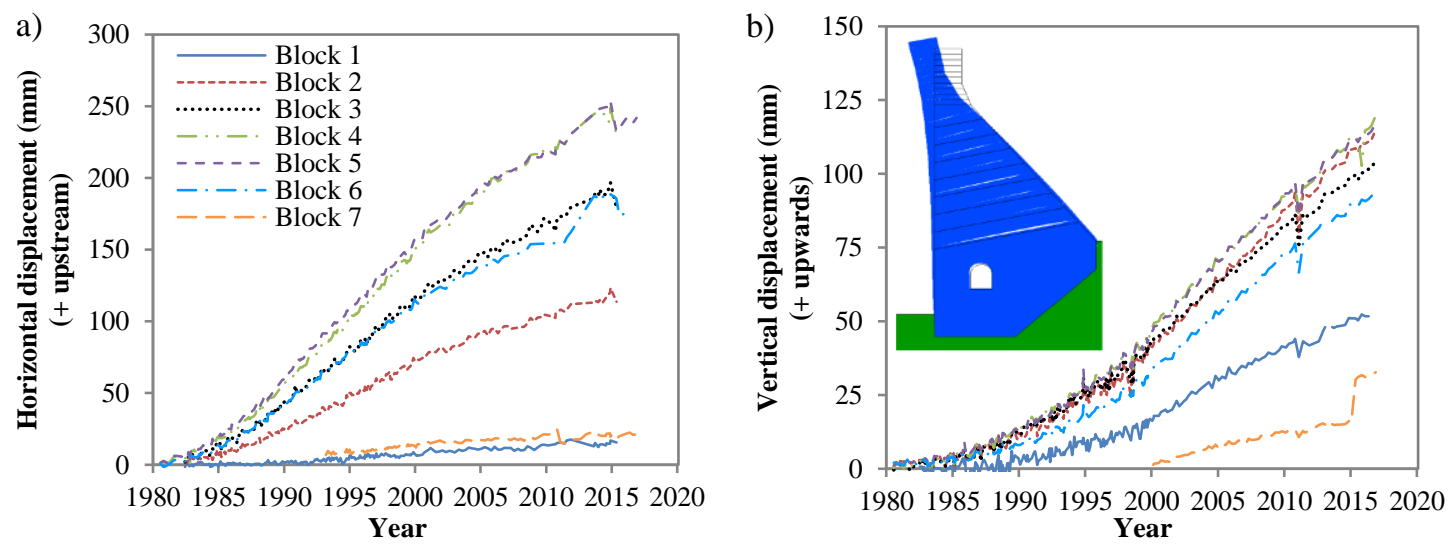

Figure 4. Evolution of a) horizontal and b) vertical displacements including a schematic representation of the displacements [11]. 


\subsection{Diagnosis}

The early studies performed in 1993 suggested that an internal sulphate attack (ISA) was the main cause of the phenomena described in the previous section. This was confirmed by the microstructural analyses, which revealed the presence of iron sulfides (pyrrhotite) in the aggregates and secondary ettringite in the interface of the aggregate and the cement paste [1214]. An incipient AAR was also detected at the time; however, its intensity was still very limited to justify the movements registered.

Oxygen plays a major role in the ISA, being essential to generate the primary reaction of pyrrhotite oxidation and the release of the sulphates that enable the formation of secondary ettringite. Therefore, the expansion is localized in the faces of the dam in contact with this gas, that is, mainly the downstream face. By contrast, the expansion in the submerged area of the upstream face and in most part of the inside of the dam is negligible due to the lack of oxygen. A strain gradient appears between the upstream and the downstream faces, leading to a curvature towards the reservoir that causes significant horizontal displacements accompanied by much smaller vertical movements (as depicted in the scheme in Figure 4.b). The ISA presents faster kinetics than the alkali-aggregate reaction (AAR) and is the main cause of the displacements registered up to 1993.

However, a different trend is observed from 1993 to 2017. While horizontal displacements at the crest of Block 5 increased by almost threefold, vertical displacements increased by fivefold (see Figure 4). Additionally, in 2009, cracks in the vertical shafts and non-recoverable displacements (approximately $10 \mathrm{~mm}$ ) in the gallery were also observed. This gallery is located at a low level, near the reservoir and close to the upstream face, where the availability of oxygen should be limited. Such evidence contradicts the expected due to the ISA, suggesting the presence of another deleterious phenomenon.

The AAR is an expansive reaction that requires a minimum humidity and commonly shows a slower kinetics than the ISA. Since the humidity is high in most areas of the dam, the AAR could enable a generalized expansion, causing a significant vertical displacement and a small horizontal displacement with direction and magnitude that depends on the shape of the dam and the location of the measurement point. This is consistent with the evidence mentioned previously for the period comprehended between 1993 and 2017. Therefore, the hypothesis consisted of a first period dominated by the ISA with a predominance of horizontal movements towards the upstream and a subsequent period dominated by the AAR with a predominance of upwards vertical displacements. The fact that the two reactions have different kinetics would explain why an incipient AAR was detected in early studies.

To verify this hypothesis, samples extracted from the dam in 2011 were characterized by scanning electron microscopy (SEM). As an example of some of the results obtained in this study, Figure 5 shows SEM images of two samples. Figure $5 \mathrm{a}$ and $5 \mathrm{~b}$ show a pore of the concrete matrix with ettringite needles (confirmed by Energy Dispersive X-Ray Analysis - EDX), potentially a consequence of the ISA. Figure $5 \mathrm{c}$ and $5 \mathrm{~d}$ show a region of the sample where alkali-silica gel from the AAR was found (confirmed by the EDX analyses). In several samples, the gel was covering the ettringite needles, thus suggesting that the ettringite was formed prior to the gel. These findings support the hypothesis described above, suggesting that the bulk of the ettringite 
formation due to the ISA came first and was succeeded by the gel formation in the AAR. This hypothesis was also confirmed through numerical simulations [15].
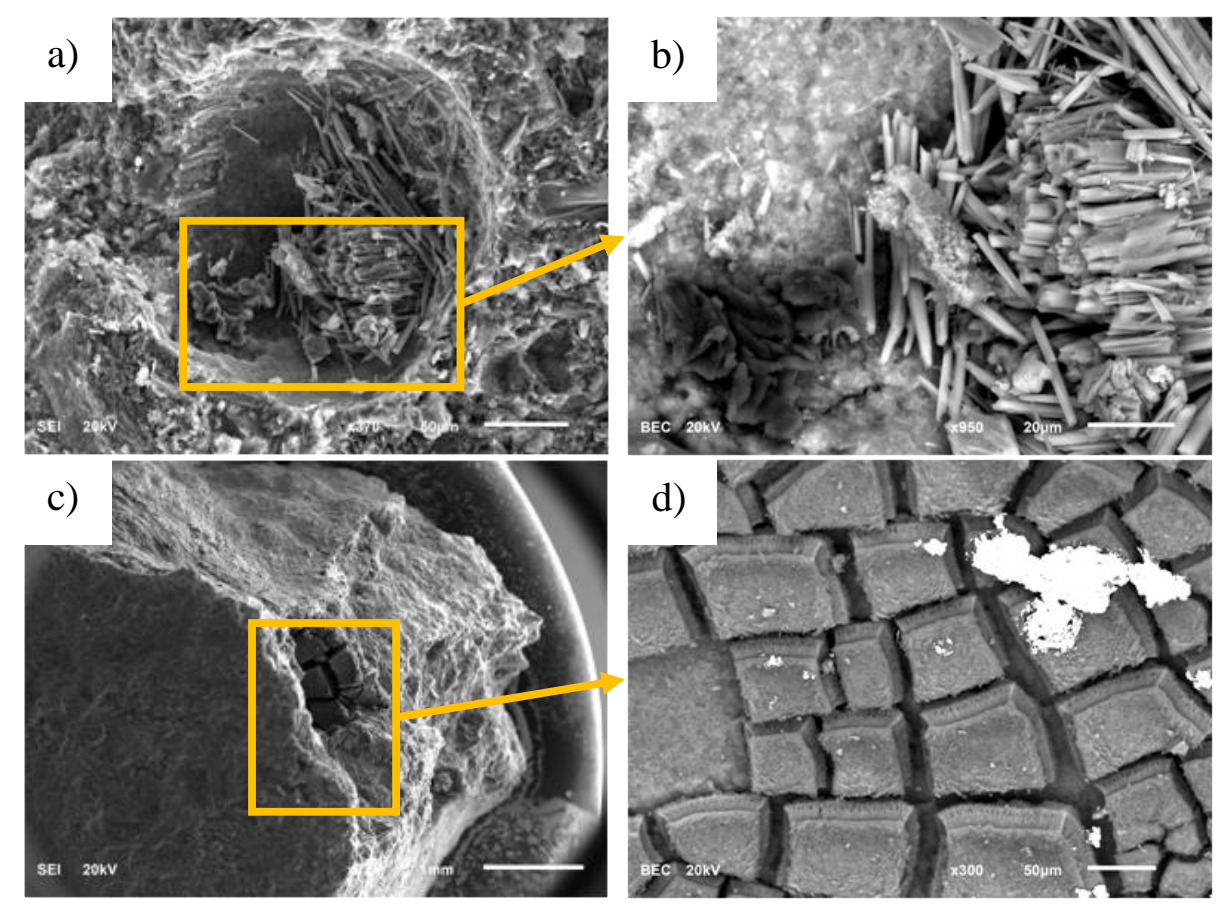

Figure 5. SEM from samples of concrete from the dam: a) pore, b) detail of the pore with ettringite, c) area with alkali-silica gel and d) detail of the area confirming the presence of the gel.

\section{CASE STUDY II: CONCRETE DAM WITH DEF AND AAR}

\subsection{Characteristics of the dam and current state}

Case study II covers a $100 \mathrm{~m}$ long and $14 \mathrm{~m}$ high gravity dam built in 1955 . A plain concrete Creager spillway provides support to reinforced concrete (RC) diaphragms walls, connected to a RC slab of a road bridge (see Figure 6a). A concrete stairway located in the central span of the bridge leads to the control valves. Consolidated soil dykes on both sides of the river, made by unreinforced concrete retaining walls, provide access to the bridge.
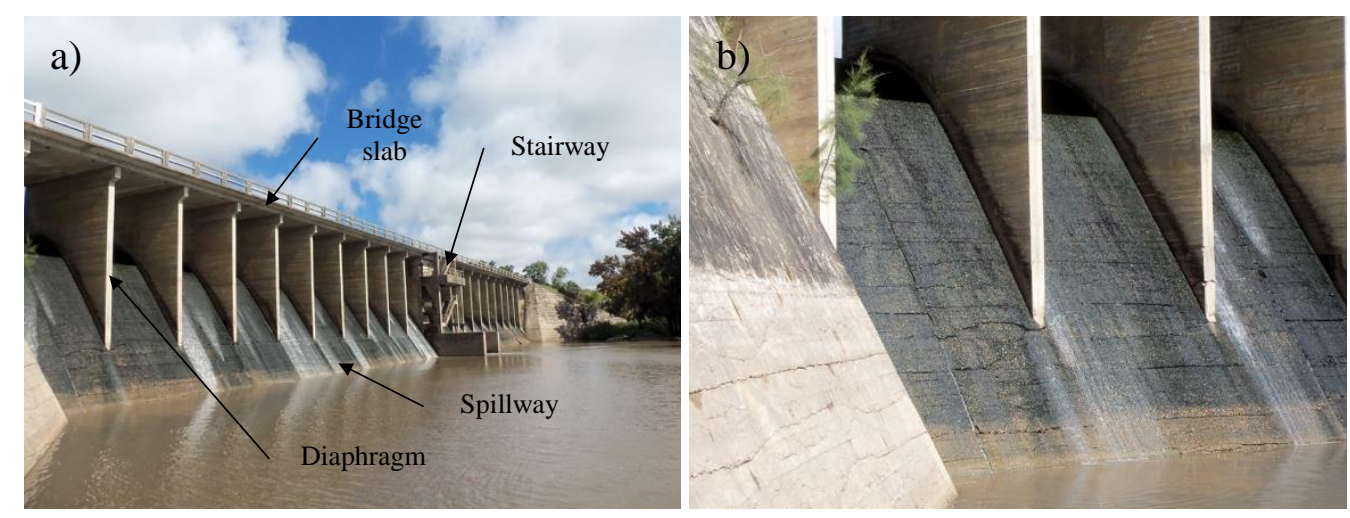

Figure 6. a) General view of the downstream face and b) detail of the horizontal cracking in the spillway and retaining walls. 
At the time of the study, the spillway exhibited horizontal cracks along the construction joints in the downstream (see Figure 6b) and visible area of the upstream faces. These cracks were already reported in 1989 and 1996, being described as non-continuous since no water egress was identified. Map cracking was also observed at the upstream face (see Figure 7a) and the walls of the dykes (see Figure 7b).
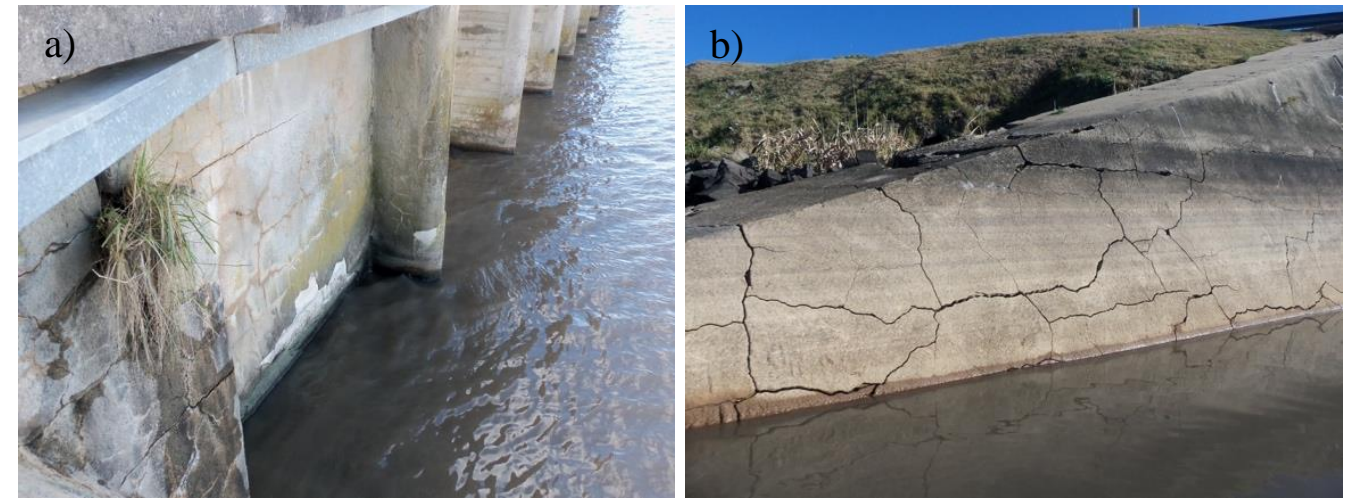

Figure 7. a) Map cracking in the upstream face and b) at the walls of the dykes.

The RC diaphragms walls show signs of surface erosion, corrosion of the reinforcement and cracking that develop perpendicular to the spillway. Some of the joints exhibit vertical cracks associated with the corrosion of the reinforcement. The bridge was not severely damaged; however, some cracks were observed on the lower surface of the RC slab. The direction of the cracks (perpendicular to the axis of the bridge) suggests that these may correspond to cold joints. Evidence of damage such as loss of concrete cover and corrosion of the reinforcement were observed in the structure of the stairway. Horizontal cracks and map cracking are detected in the retaining walls of the dykes in the downstream face (see Figure 6b). Nevertheless, in the upstream face, only map cracking is observed.

\subsection{Diagnosis}

According to the diagnostic procedure presented in Table 1, the first step in stage 1 is the analysis of the "clinical history" including the historical information. A report from the 1950's with descriptions of the original project and construction plans was the only document available. It included information about the pouring (temperatures), the joints (dimensions of the layers) and the curing (procedure and time). The application of these recommendations could not be confirmed due to the lack of data on the construction.

The information regarding the material used in the construction was vague and incomplete. The only reference to the type of cement indicated that "the Portland cement will be of slow setting" and "cement that was previously stored will not be employed". Again, there is no evidence that this type of cement was used in the construction of the dam since records from the construction period were not available. Moreover, slow setting cement were first introduced in the country for the construction of another concrete dam only in 1974. These uncertainties regarding the origin and type of cement represent a drawback in the diagnosis given that the amounts of gypsum, alumina phases and alkali in the cement are unknown.

The historical documents regarding the operation and management period revealed that repair and maintenance operations due to horizontal cracking of the spillway had already taken place during 
the 1960s, only one decade after the dam was constructed. Furthermore, the dam had no monitoring equipment to register the behaviour throughout the years.

Although the lack of information hampers the diagnostic procedure, it is still possible to identify the causes of the damage observed in the dam. The field inspection, experimental studies and numerical tools are the steps to follow (according to stage 2 of the diagnostic procedure, see Table 1). The experimental study consisted of mechanical tests and microstructural analyses of aggregate and mortar obtained from concrete cores extracted from the dam. For the sake of brevity, the description here will focus on the results of the microstructural techniques that included the assessment of the composition of the aggregates through XRD analyses and petrographic examination, as well as the evaluation of mortar samples with XRD and SEM.

Among the 16 aggregate samples analysed with XRD, 12 were identified as quarzitic rocks given that quartz was the main crystalline phase. Feldspar was also detected as a minor phase in 11 of the quarzitic samples but it was not possible to identify the specific type of feldspar. The other aggregate samples were quarzitic schists with a large presence of feldspars (albite) and variable quantities of mica (muscovite). No other crystalline phases were identified. Figure 8a shows the XRD patterns of the quartzitic schists. The analyses of five thin sections with the optical microscope confirms the presence of quartz, albite and mica. Undulate extinctions, which are a characteristic feature from quarzitic samples with small size crystals and dislocations, were also identified (see Figure 8c). Additionally, one sample exhibited a fibrous structure that is typical of chalcedony with microcrystalline grains (see Figure 8b). Also, some of the samples with feldspars contained clayey phyllosilicates, which is a sign of alteration.
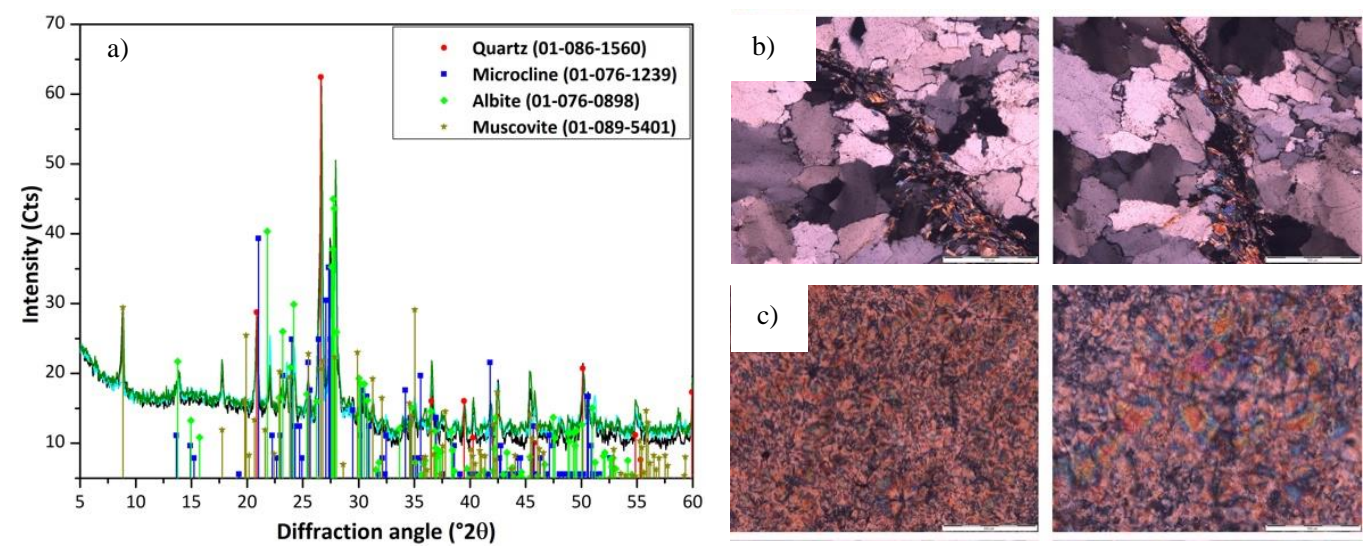

Figure 8. a) XRD patterns of the quartzitic schists, b) quarzitic aggregate sample with the presence of chalcedony and c) undulate extinction characteristic from quartz.

All the above indicates that the aggregates selected are not adequate to produce concrete, suggesting a potential reactivity with the alkalis of the cement. Even though amorphous silica was not observed, other characteristics described in the literature as signs of possible alkali-silica reactivity were detected. Moreover, the reactivity of the aggregates was confirmed through accelerated mortar bar tests [16]. Further detail on the tests and the results obtained may be found in [1].

Concrete samples from 7 cores drilled from several elements of the dam ( 2 from the spillway, 2 from retaining walls, 2 from the diaphragms and 1 from the wall of the stairway) were evaluated. The samples from the RC diaphragms walls did not exhibit any sign of degradation. The portlandite found in the samples display an intense reflection that may be associated with the use 
of a cement with high clinker content. The XRD analyses also revealed the presence of different monosulphoaluminate phases and a low intensity of the ettringite, which are evidence of the normal conversion of Aft phases into Afm over the time.

Differently, from the previous samples, the remaining samples presented cracks along the cement paste and the aggregates with white precipitates inside pores, which are evidence of an expansive reaction. The findings of the XRD analyses support this hypothesis. Similar characteristics were detected in terms of crystalline phases, both in the altered and sound samples. The high intensity of the ettringite reflections compared to the previous samples reveal that a significant amount of ettringite did not transform into Afm phases. Additionally, the peaks associated with the portlandite exhibit low intensity. Finally, okenite, which has been identified by other authors [17] as a crystalline phase of the ASR, was a minor phase in some of the mortar samples.

Abundant AAR gel was found in the SEM and EDX analyses of all samples (see Figure 9a). The high relative intensities of potassium and calcium peaks suggest the reaction was in an advanced stage since the concentration of these ions in the gel tends to increase as the reaction progresses [18]. In some cases, the gel appeared together with ettringite, which was dispersed in the cement paste and precipitated in pores (see Figure 9b). In some samples, ettringite needles are covered by different neoformed products whose morphology and composition suggest a product of the ASR in an initial stage of the reaction (see Figure 9c). Ettringite was also found in the form of long, well-defined needles inside pores (see Figure 9d).
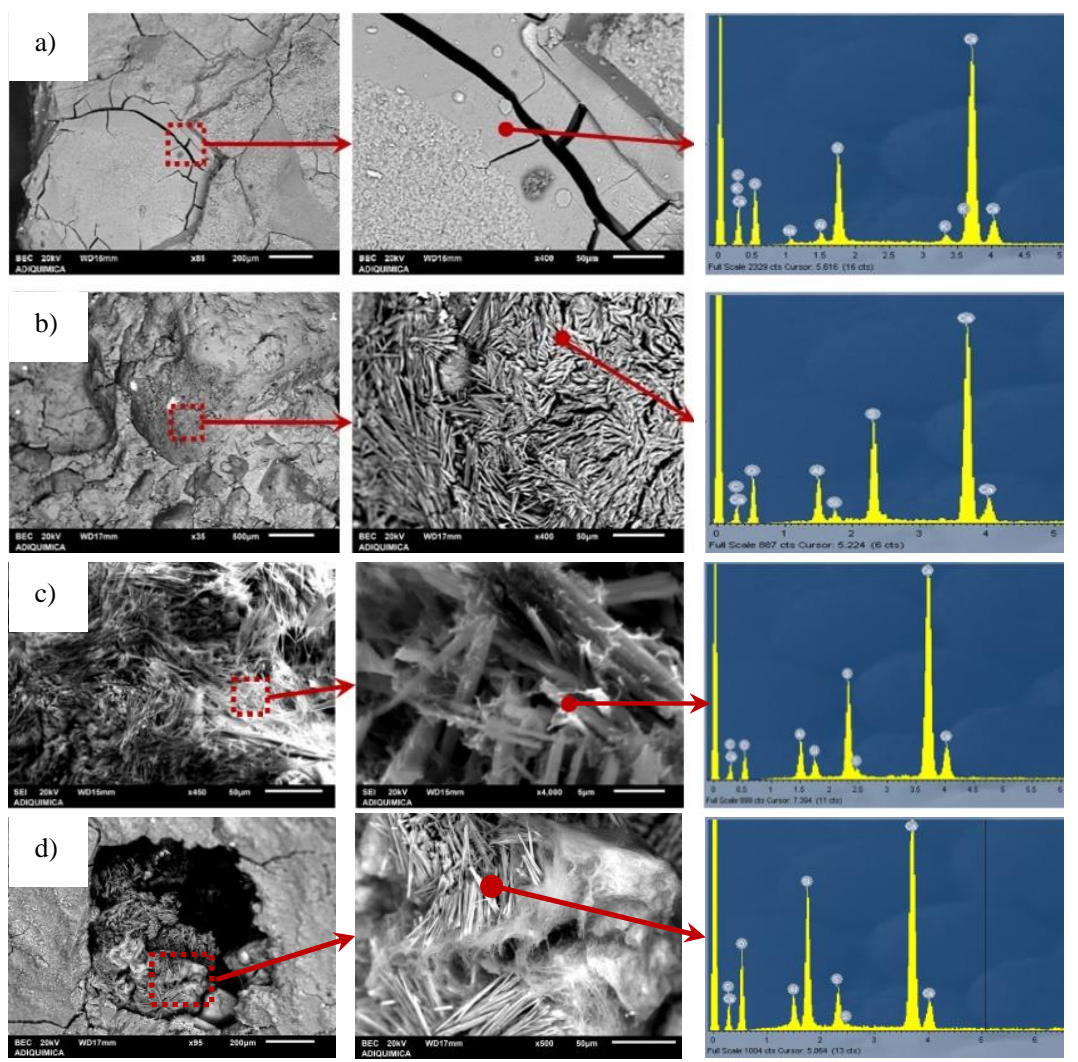

Figure 9 SEM images of mortar samples: a) AAR products, b) ettringite, c) ettringite covered by AAR products and d) long ettringite needles inside a pore.

The high content of ettringite and its distribution throughout the matrix suggest a delayed ettringite formation (DEF). Previous studies reporting DEF show similar SEM images [19,20]. 
The DEF is a phenomenon that occurs when the temperature during construction and curing exceeds $70^{\circ} \mathrm{C}$, thus blocking the normal formation of ettringite during the first hours of hydration. Instead, ettringite forms at later ages once the temperature drops and water is available to mobilize the ions. At this stage, the microstructure has limited space to accommodate the ettringite that produces internal stresses and may lead to expansions [21-23].

The high temperatures in the dam may be attributed to the use of a high clinker content in the concrete composition. In addition to that, other authors [24] have linked the hydrogarnet in the XRD analyses with a long curing process of concrete at high temperatures. Another argument in favour of this hypothesis is the fact that the ettringite was fossilized by the AAR product, thus indicating DEF must have taken place early in the service life of the dam.

In the study conducted by the authors, a thermal simulation was performed to assess the likelihood of the concrete temperature exceeding $70^{\circ} \mathrm{C}$ during construction. The modelling confirmed that it is highly probable that such temperature was exceeded, thus leading to DEF and the early horizontal cracking observed in the spillway. Finite element models confirmed that the volumetric expansion in the spillway due to DEF and ISA generated tensile stresses that led to the cracking pattern observed in the RC diaphragm walls. Further detail on the experimental techniques, modelling and results may be found in [1].

\section{CASE STUDY III: CONCRETE DAM WITH LOCALIZED EXPANSIONS}

\subsection{Characteristics of the dam and current state}

Case study III was selected given the peculiarities of the internal sulfate attack in the dam, which is not generalized in the downstream face but localized in certain areas where a specific type of aggregate was used. This study corresponds to an arch-gravity dam (see Figure 10a) built in 1969 that is $72,6 \mathrm{~m}$ high and whose crest is $195 \mathrm{~m}$ long. The dam is divided into 12 blocks containing 4 main longitudinal galleries connected by an additional perimeter gallery. The reservoir has a capacity of $3 \mathrm{hm}^{3}$. The dam is in an area with sedimentary and metamorphic rocks such as slate and limestone (in some cases with calcite veins or quartz). The historical records indicate that the concrete was produced with aggregates from the area, extracted from 2 different locations of the same quarry (see Figure 10b).
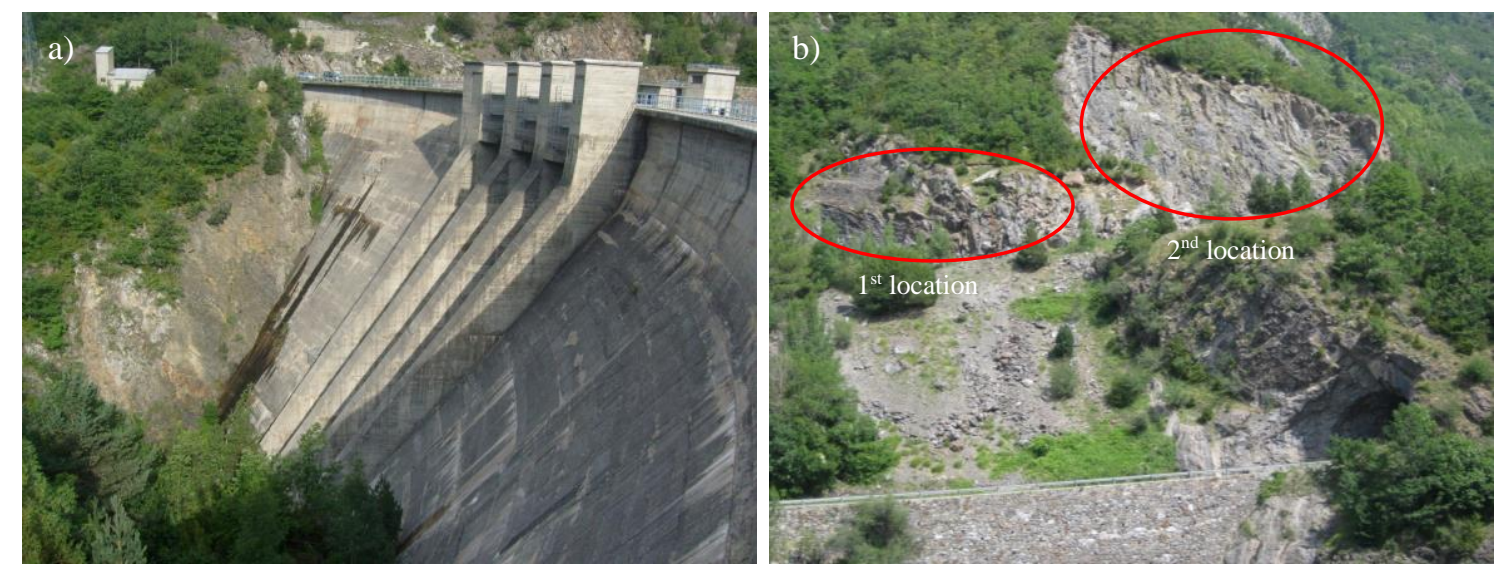

Figure 10. a) General view of the downstream face in 2008 and b) view of the quarry and locations for the extraction of aggregates. 
In the visual inspection, degradation due to different phenomena was observed in the downstream face. On one hand, superficial damage due to freeze-thaw cycles was detected, as shown in Figure 11b. On the other hand, map cracking and ochre shading precipitates appeared in the blocks near the abutment (Figure 11a and 11b), both in the downstream face (Figure 11c) and in the entrance to the upper gallery (Figure 11d).
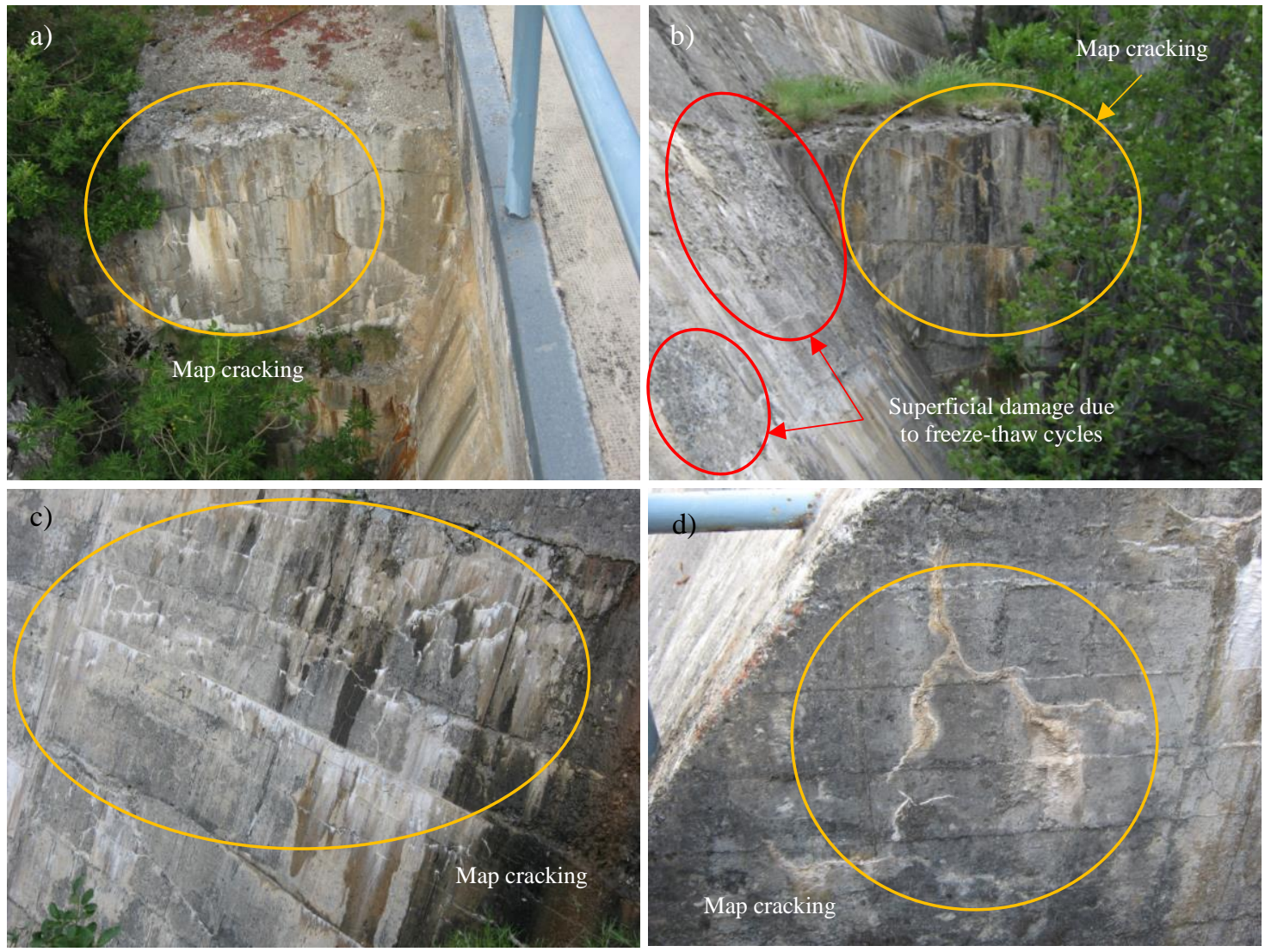

Figure 11. Map cracking localized in specific areas of the dam: a) block beside the right abutment, b) block beside the left abutment, c) downstream face and d) entrance to the upper gallery.

Inside the dam, oblique cracks were observed in the upper gallery (level $1350 \mathrm{~m}$ ) near the left abutment, as shown in Figure 12a. In the second gallery (level $1330 \mathrm{~m}$ ), inside the right abutment, the rock exhibits signs of oxidized iron sulfides (see Figure 12b). This phenomenon was also detected in the two lower galleries (at levels $1311 \mathrm{~m}$ and $1292 \mathrm{~m}$ ).
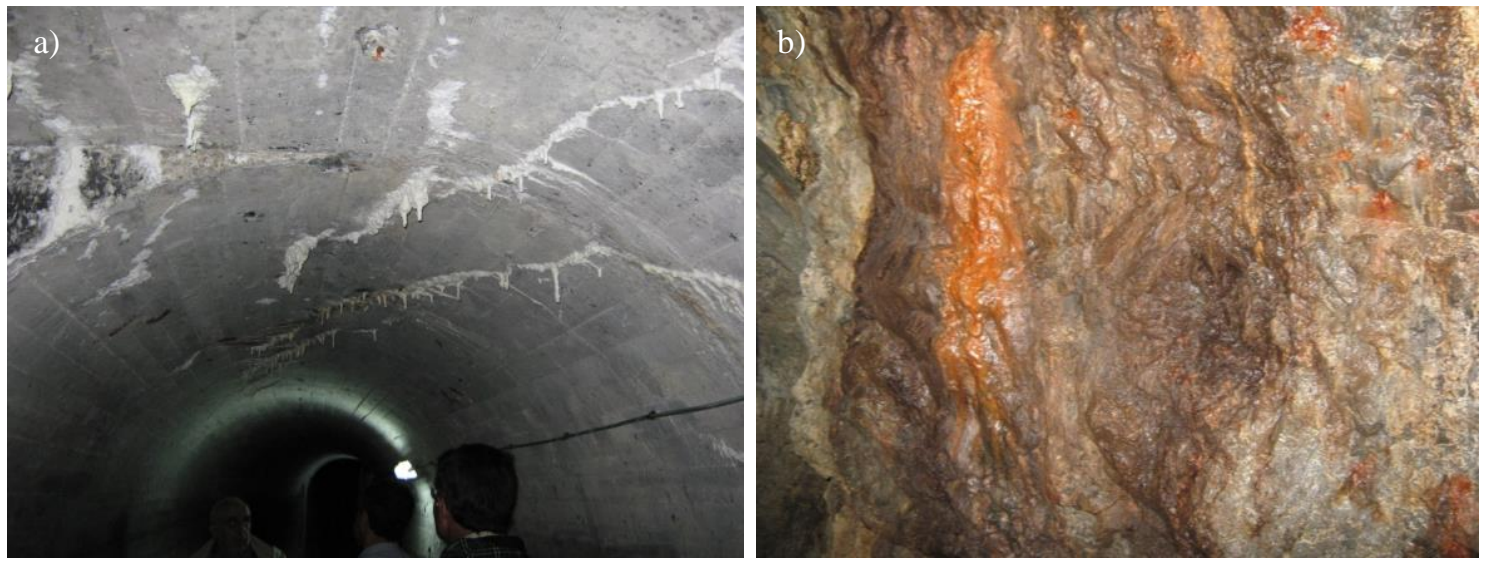
Figure 12. a) Oblique cracks in an upper gallery near the left abutment (level $1350 \mathrm{~m}$ ) and b) state of the rock in the right abutment seen from the second gallery (level $1330 \mathrm{~m}$ ).

Besides the visual inspection of the dam, the historical records and the data registered during the years of monitoring the dam were analysed, revealing an unusual behaviour. Figure 13.a shows the location of the points of measurement and the evolution of the vertical (Figure 13.b) and horizontal (Figure 13.c) displacements. Notice that there is a 1-year difference between the vertical and the horizontal measurements.

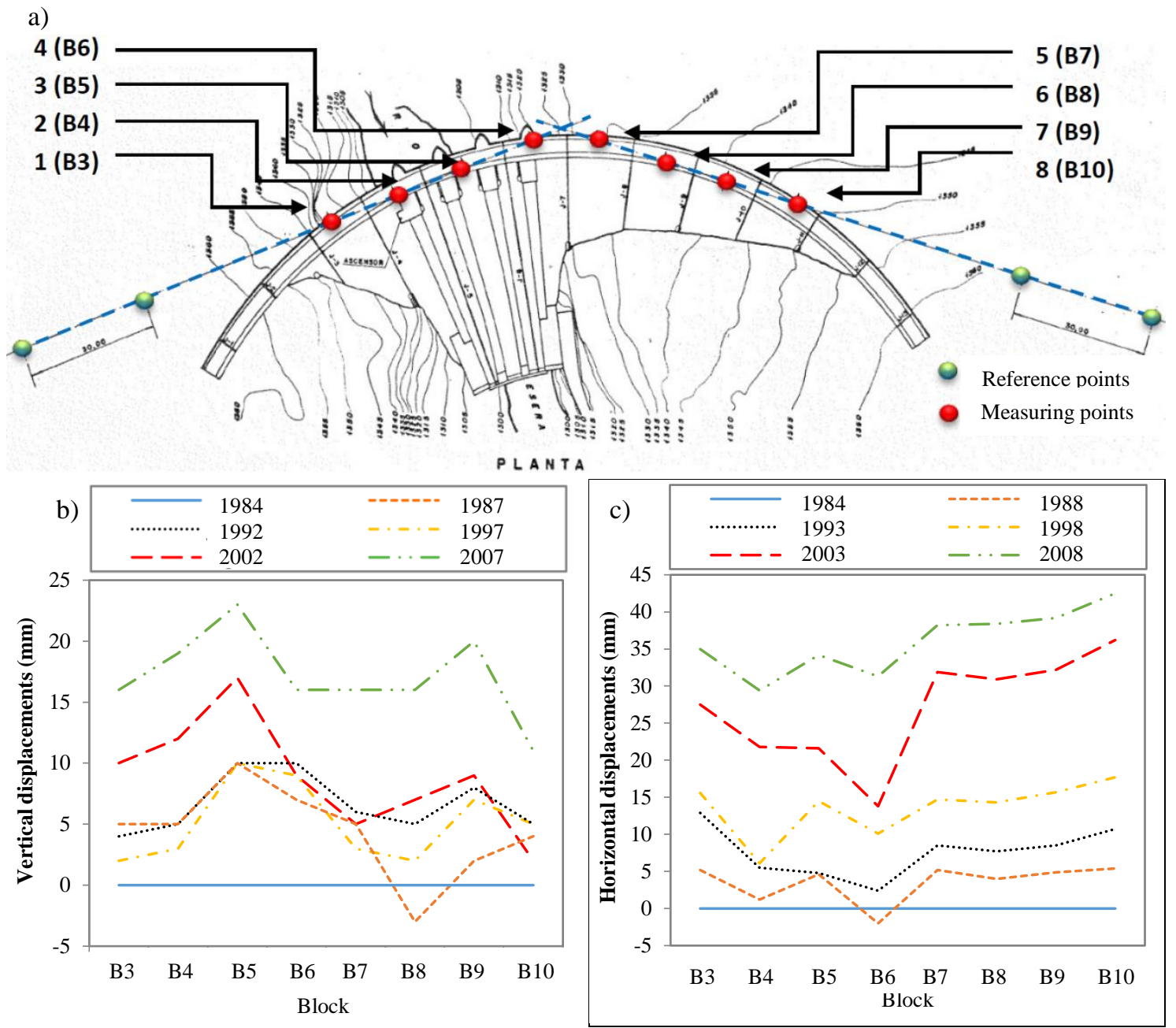

Figure 13. a) Location of points of measurement and blocks [11] and b) vertical and c) horizontal displacements per block at the crest of the dam.

The curves indicate that the displacements of the dam are non-recoverable, reaching vertical values of $23 \mathrm{~mm}$ in B5 and horizontal values of $42.5 \mathrm{~mm}$ in B10. Notice that displacements caused by expansive reactions are usually symmetric when plotted as in Figure 13 (if the dam is symmetric) and proportional to the height of the dam (see case study I). In other words, the central blocks usually present the largest displacements with regards to the blocks near the abutment, which contradicts the behaviour observed in this case study. Consequently, the curves in Figure 13 suggest that, in this case, the dam presents a non-uniform response either due to the material or the interaction with the soil.

\subsection{Diagnosis}


This dam is an example of the importance of reviewing "clinical history" to reach a successful diagnosis (see Table 1). Historical records indicate that the aggregates used in the concrete were obtained from two locations at the quarry near the dam (see locations in Figure 10b). Figure 14 depicts the areas of the dam constructed with aggregate from each location and the position of the most significant damage found in the visual inspection conducted in 2008. The aggregates extracted from the first quarry location shown in Figure 10b where used to produce the concrete for the first stage of construction (hatched areas in Figure 14). Aggregates from the second quarry location shown in Figure 10b were used in the following construction stages (white area in Figure 14). Interestingly, all signs of damage were detected in areas corresponding to the initial stage of construction.

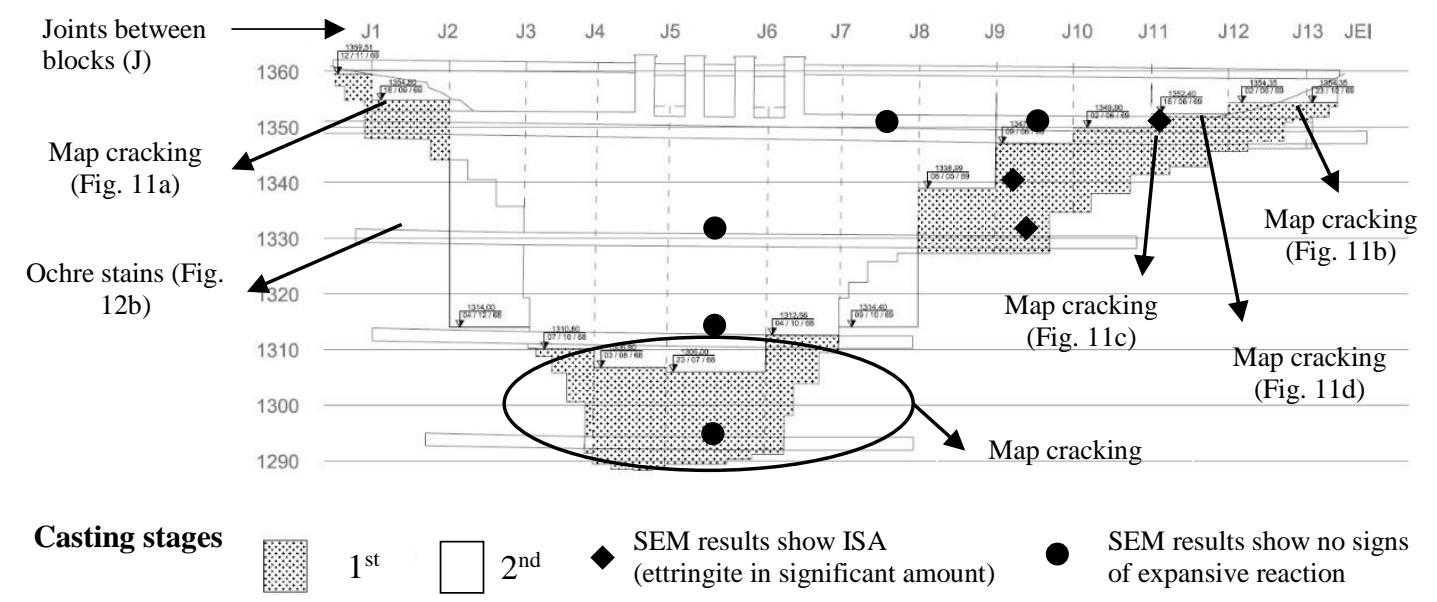

Figure 14. Stages of construction depending on aggregates used.

Therefore, it is possible that the aggregates used during the first stage of construction were potentially more reactive and led to expansive reactions in the concrete. This hypothesis was supported by the current state of the rocks in the quarry, which exhibited signs of oxidization of iron sulphides in the first location, whereas rocks in the second location remained unaltered. An experimental program was conducted on concrete samples extracted from the dam using SEM and EDX to verify the presence of an expansive reaction. Figure 14 shows the location of the extraction points classified as without (marked with the symbol $\bullet$ ) or with (marked with the symbol ) signs of expansive reaction based on the microstructural and mineralogical analysis. All samples with signs of expansion were in the region within the $1^{\text {st }}$ construction stage, having iron sulfides in the form of pyrite and a significant amount of secondary ettringite either filling cracks and pores or on the surface.

Figure 15a shows iron sulfides in a sample located in the second gallery (level $1330 \mathrm{~m}$ ) between J9 and J10, near the left abutment (see Figure 14). The microanalysis with EDX confirmed this was pyrite. Figure $15 \mathrm{~b}$ shows ettringite needles found in the same sample. Figure $15 \mathrm{c}$ corresponds to a sample obtained from the upper gallery (level $1351 \mathrm{~m}$, see Figure 14) also in the area cast during the $1^{\text {st }}$ stage and shows a significant amount of ettringite needles. Figure $15 \mathrm{~d}$ was obtained from a sample that exhibited a halo around the aggregate associated to a possible AAR. The SEM and EDX analyses confirmed the presence of AAR gel and ettringite needles. The limited formation of gel suggests an incipient AAR. 

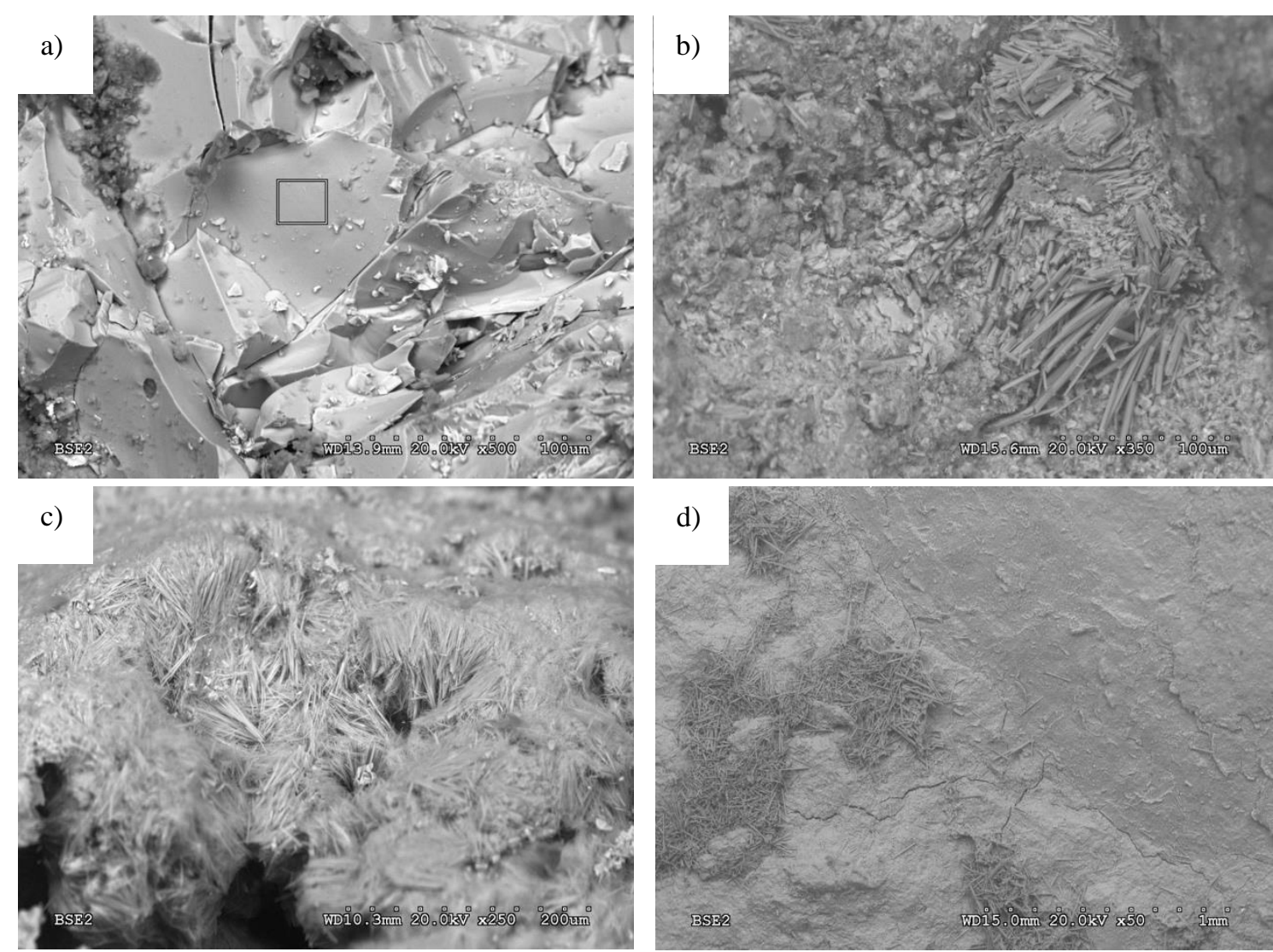

Figure 15. a) Iron sulfides, namely pyrite, b) c) ettringite needles and d) ettringite needles and AAR gel.

Such outcome confirms an ISA in the concrete corresponding to the first stage of construction due to the iron sulfides contained in the aggregates used at that stage, which justifies the unusual characteristics of some of the signs of damage (e.g. map cracking localized in certain areas downstream face and the non-symmetry displacement of the dam).

In the upper gallery near the left abutment, the dam exhibits oblique cracks that are usually associated with torsion forces. Torsion may occur in a block of the dam due to differential displacements within the block or due to the interaction with the abutments or other blocks that exhibit different behaviour. The fact that the expansions due to ISA are localized in certain areas of the blocks (hatched region in Figure 14) supports this argument. Furthermore, in the case of the cracks located in the upper gallery, the block between joints $\mathrm{J} 12$ and J13 presented clear signs of ISA (see Figure 12b) and could, consequently, contribute to a torsion effect of adjacent blocks.

\section{CASE STUDY IV: CONCRETE DAM-SOIL INTERACTION}

\subsection{Characteristics of the dam and current state}

Case study IV corresponds to a straight gravity dam built between 1957 and 1964, with a height of $40 \mathrm{~m}$ and a crest length of $93 \mathrm{~m}$ (see Figure 16a). The dam has 8 blocks with different widths and height (ranging from $8.5 \mathrm{~m}$ to $17.0 \mathrm{~m}$ ), being connected by the same gallery. The spillway is in the central blocks that are $17 \mathrm{~m}$ wide each. The reservoir has a capacity of $0.050 \mathrm{hm}^{3}$. The dam is in an area where slates are the predominant rocks. 

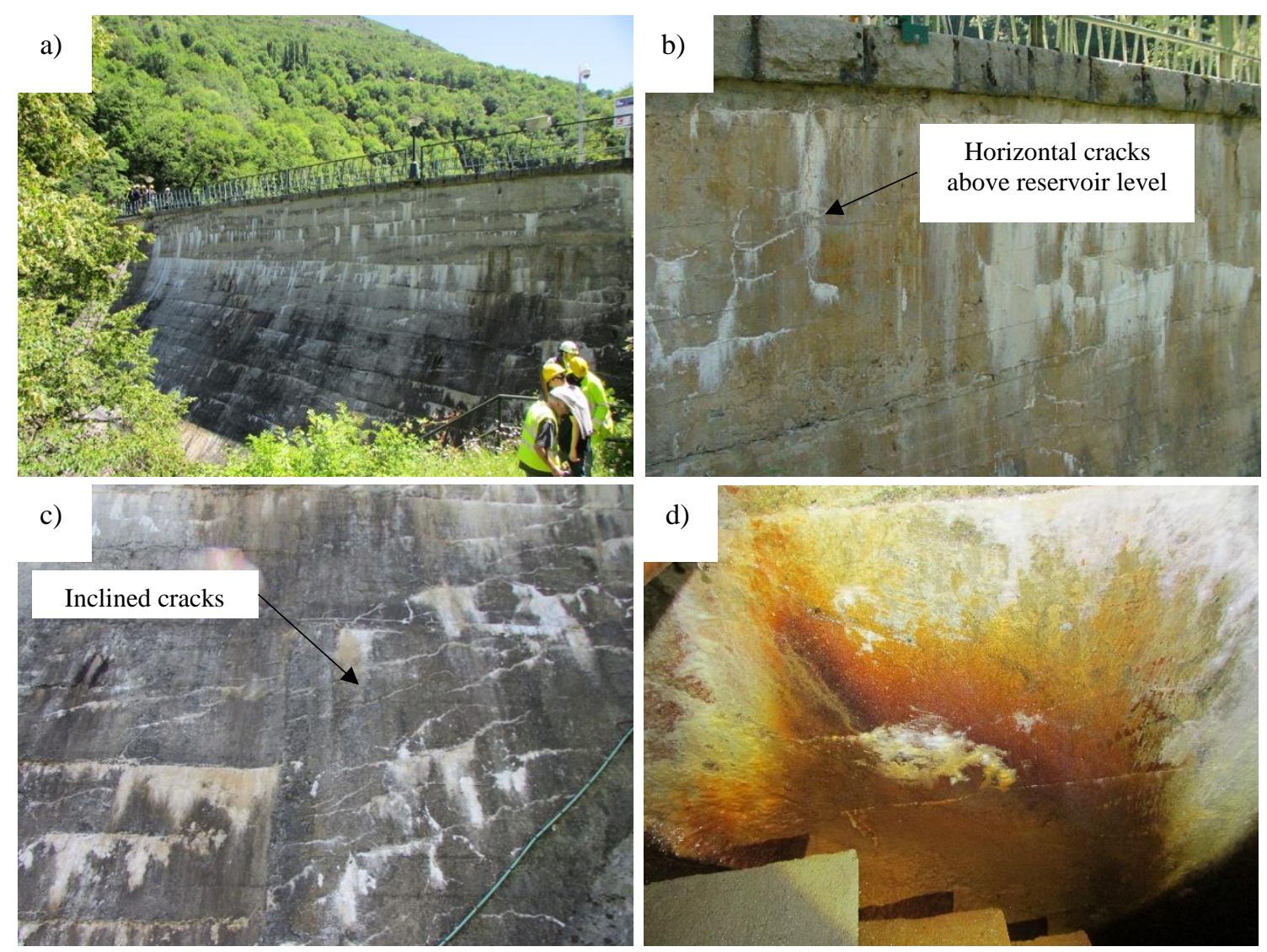

Figure 16. a) General view of the downstream face, b) map cracking at the downstream face, c) inclined to crack near the abutment, d) stains associated with oxidization of iron sulphides at gallery wall.

Field inspections conducted over the years revealed map cracking in the downstream face and auxiliary elements of the dam. Either horizontal (see Figure 16b) or slightly inclined cracks were observed near the crest of the dam, at the downstream face. The inclination of these cracks increases near the abutments, as shown in Figure 16c. Despite the application of a waterproofing layer during maintenance operations, a photograph taken in 1984 confirmed the existence of these cracks also in the upstream face above the water level. The white precipitates in the cracks (Figures $16 \mathrm{~b}$ and 16c) indicate the accumulation of calcium carbonate. In the gallery of the dam, horizontal cracks were also detected on both walls (on the downstream and upstream sides). Additionally, the concrete walls exhibited stains commonly associated with the oxidization of iron sulphides, as shown in Figure 16d.

Figure 17 shows the displacements measured at the crest of the dam from 2000 to 2017 (previous measurements were not available). The analysis of the data reveals non-recoverable movements, beyond the cyclic variations due to thermal effects or the level of the reservoir. The central blocks of the dam (Blocks 4 and 5) accumulated horizontal displacements towards upstream of $20 \mathrm{~mm}$ in the period (monitoring points P4 and P5 in Figure 17a, respectively). The opposite behaviour is detected for the blocks located near the abutments that presented either displacement with small variations around $0 \mathrm{~mm}$ (monitoring point $\mathrm{P} 7$ near left abutment) or towards downstream (P1 near the right abutment). Figure $17 \mathrm{~b}$ indicates that all monitoring points, except for P1, register a nonrecoverable upward movement of the blocks. This elevation ranges from 20 to $25 \mathrm{~mm}$ in the period considered. Considerable smaller vertical displacements are observed in P1, near the right abutment. This may be attributed to the smaller size of the block combined with the influence of the restraint applied by the rock. 

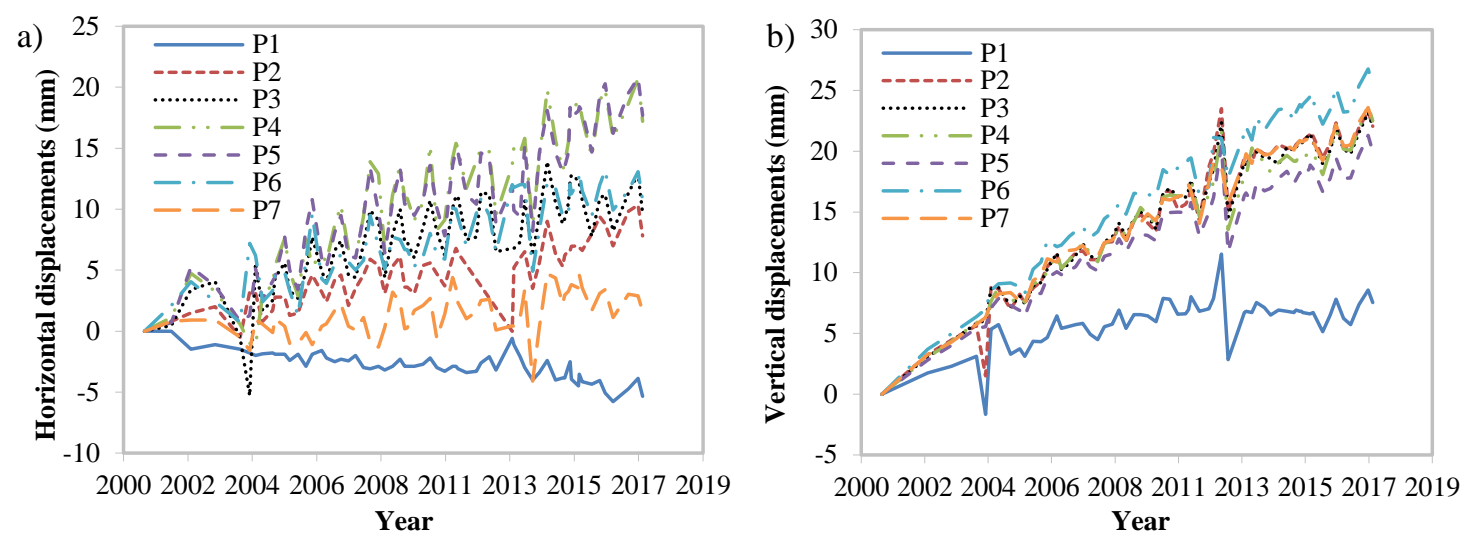

Figure 17. a) Horizontal and b) vertical displacements registered in the period 2000-2017.

\subsection{Diagnosis}

Several pieces of evidence described previously are consistent with an ISA, including map cracking, oxidization of iron sulphides and non-recoverable displacements towards upstream. The study of the historical records indicates that the aggregates used in the concrete were extracted from the local area, which according to the geological maps is predominantly constituted by slate and limestone. Moreover, during the field inspection of the gallery, rocks located in the left abutment exhibited signs of oxidization (see Figure 18a).

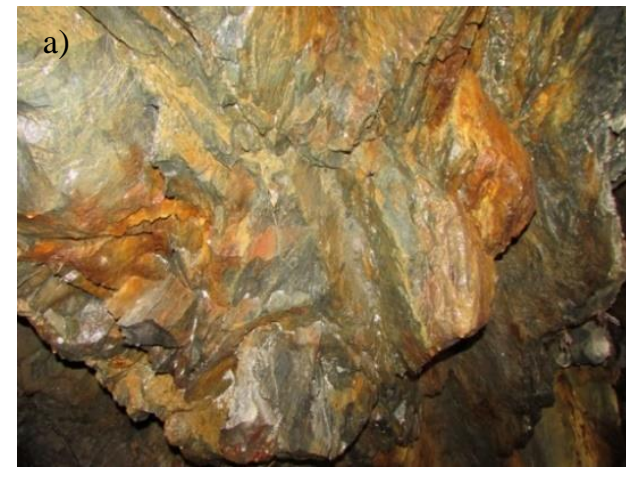

b)

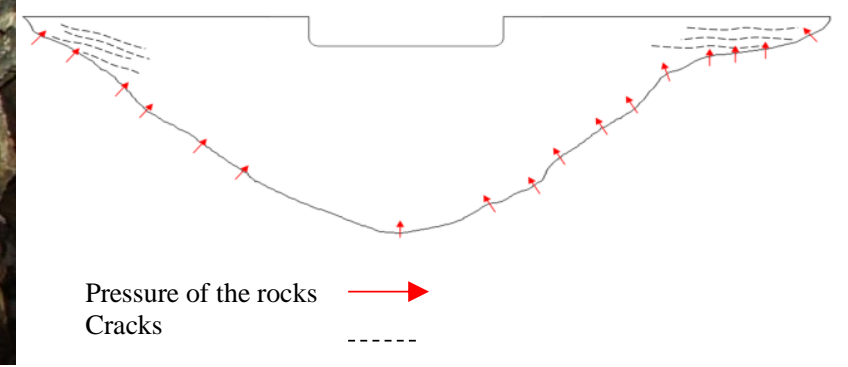

Figure 18. Detail of a) rock on left abutment and b) effect of the pressure of the abutments on the dam.

Rock samples extracted from the abutments and aggregates extracted from the concrete were characterized through XRD and SEM to evaluate the presence of potentially expansive products. The analyses reveal veins of iron sulphides (pyrrhotite) cutting through the schists of the rock. This indicates the aggregate and the surrounding rock might trigger expansive movements. In this case, the expansion from the concrete and the movements induced by the oxidation of the surrounding rock (see Figure 18b) might contribute to the displacements of the dam. The contribution of the surrounding rock could explain the cracks near the abutments and the movements observed at P1 for Block 1 [25].

\section{CONCLUSIONS}

The present paper covers the lessons learned during 30 years of studying and diagnosing around 15 concrete dams with pathologies. The diagnostic procedure developed is briefly presented and 
applied in four of the most interesting case studies encountered over the years. The main conclusions derived from the study are presented below.

- The field inspection is an essential tool to detect possible pathologies in concrete dams. Although experimental verifications are mandatory to provide an accurate diagnosis of dams with expansive reactions, several pieces of evidence associated with these pathologies may be spotted in the field inspection.

- Different types of expansive reactions also differ in terms of magnitude (in terms of expansion and, therefore, displacements of the dam) and timescale. Identifying the magnitude and timescale is essential to provide an accurate diagnosis. Displacements due to expansive reactions tend to be proportional to the height of the block of the dam. If this is not the case, displacements might be caused by a localized phenomenon. The continuous monitoring of the dam is a fundamental step to confirm or review the diagnosis over the years.

- The lack of historical records and monitoring data is an obstacle in the diagnostic procedure that can be sidestepped using complementary methods. In this regard, being able to track oral sources (e.g. people involved in the construction) can provide valuable information.

- Cracks and significant displacement in blocks close to the abutments suggest a dam-soil interaction and, therefore, the geological and geotechnical characteristics of the area should be analysed to assess this hypothesis.

- A positive outcome in one specific test or verification is not enough to establish conclusively that the damage is caused by a certain pathology. The diagnostic procedure must demonstrate a cause-effect relationship between the pathology and the structural behaviour/damage, summing different pieces of evidence that support such an explanation. If this relationship is not proven, the pathology will be considered as secondary, possibly coexisting with another main cause of the damage.

\section{ACKNOWLEDGEMENTS}

This document represents a small part of the work developed over more than 30 years. In that period many have been involved and have collaborated, from the engineers in the companies, owners of the dams, to the academics and researchers at the university. The authors acknowledge the dedication of all those who, throughout the years, was somehow involved in these studies.

The authors acknowledge the economic support provided by the Spanish Ministry of Science and Innovation through the project BIA2013-49106-C2-1-R.

\section{REFERENCES}

[1] Jansen, R. B. Advanced Dam Engineering for Design, Construction, and Rehabilitation. Springer Science \& Business Media, 2012. ISBN 9781461308577. 811p.

[2] Oliveira, I., Cavalaro, S.H.P., Aguado, A. New kinetic model to quantify the internal sulfate attack in concrete. Cement and Concrete Research, 43 (1), pp. 95-104; 2013. DOI: 10.1016/j.cemconres.2012.09.010

[3] Oliveira, I., Cavalaro, S.H.P., Aguado, A. New unreacted-core model to predict pyrrhotite oxidation in concrete dams. Journal of Materials in Civil Engineering, 25 (3), pp. 372-381; 2013. DOI: 10.1061/(ASCE)MT.1943-5533.0000531

[4] Oliveira, I., Cavalaro, S.H.P., Aguado, A. Evolution of pyrrhotite oxidation in aggregates for concrete. Materiales de Construccion, 64 (316); 2014. DOI: 10.3989/mc.2014.08413 
[5] Sanchez, L.F.M., Multon, S., Sellier, A., Cyr, M., Fournier, B., Jolin, M. Comparative study of a chemo-mechanical modeling for alkali silica reaction (ASR) with experimental evidences. Construction and Building Materials, 72, pp. 301-315; 2014. DOI: 10.1016/j.conbuildmat.2014.09.007.

[6] Sanchez, L.F.M., Fournier, B., Jolin, M., Mitchell, D., Bastien, J. Overall assessment of Alkali-Aggregate Reaction (AAR) in concretes presenting different strengths and incorporating a wide range of reactive aggregate types and natures. Cement and Concrete Research, 93, pp. 17-31; 2017. DOI: 10.1016/j.cemconres.2016.12.001

[7] Pardo-Bosch, F., Aguado, A. Damage diagnosis in concrete dams with presented expansive damage based on medical propaedeutics. Journal of Performance of Constructed Facilities, 31 (5), 04017048-1-04017048-12; 2017. DOI:10.1061/(ASCE)CF.1943-5509.0001035.

[8] Blanco, A., Cavalaro, S.H.P., Segura, I., Segura-Castillo, L., Aguado, A. Expansions with different origins in a concrete dam with bridge over spillway. Construction and Building Materials, 163, 861-874; 2018. DOI:10.1016/j.conbuildmat.2017.12.161.

[9] Campos, A., López, C., Blanco, A., Aguado, A. Structural diagnosis of a concrete dam with cracking and high non-recoverable displacements. Journal of Performance of Constructed Facilities, 30(5); 2016. DOI: 10.1061/(ASCE)CF.1943-5509.0000869.

[10] Sellier, A., Bourdarot, E., Multon, S., Cyr, M., Grimal, E. Combination of Structural Monitoring and Laboratory Tests for Assessment of Alkali-Aggregate Reaction Swelling: Application to Gate Structure Dam. ACI Materials Journal, 106(3), 281-290; 2009.

[11] Campos, A. Análisis numérico de presas de hormigón bajo acciones expansivas (Numerical analaysis of dams affected by expansive actions). Doctoral Thesis presented at Universidad Politécnica de Cataluña, Barcelona, Spain. 270 p. 2012.

[12] Chinchón, J.S., Ayora, C., Aguado, A., Guirado, F. Influence of Weathering of Iron Sulfides Contained in Aggregates on Concrete. Durability. Cement and Concrete Research, 25(5), 1264-1272; 1995. DOI: 10.1016/0008-8846(95)00119-W.

[13] Casanova, I., Agulló, L., Aguado, A. Aggregate Expansivity Due to Sulfide Oxidation - I. Reaction System and Rate Model. Cement and Concrete Research, 26(7), 993-998; 1996. DOI: $10.1016 / 0008-8846(96) 00085-3$.

[14] Casanova, I., Aguado, A, Agulló, L. Aggregate expansivity due to sulfide oxidation, II.Physico- chemical modeling of sulfate attack. Cement and Concrete Research, 27(11), 1627-1632; 1997. DOI:10.1016/S0008-8846(97)00148-8.

[15] Campos, A., López, C., Blanco, A., Aguado, A. Effects of an internal sulfate attack and an alkali-aggregate reaction in a concrete dam. Construction and Building Materials, 166, 668683; 2018. DOI: 10.1016/j.conbuildmat.2018.01.180.

[16] IRAM 1674. Agregados. Determinación de la reactividad alcalina potencial. Método acelerado de la barra de mortero. Instituto Argentino de Normalización y Certificación, Buenos Aires, Argentina (in Spanish).

[17] Dähn, R., Arakcheeva, A., Schaub, Ph., Pattison, P., Chapuis, G., Grolimund, D., Wieland, E., Leemann, A. Application of micro X-ray diffraction to investigate the reaction products formed by the alkali-silica reaction in concrete structures. Cement and Concrete Research, 79, 49-56; 2016. DOI: 10.1016/j.cemconres.2015.07.012.

[18] Godart, B., de Rooij, M., Wood, J. G. M. Guide to Diagnosis 600 and Appraisal of AAR Damage to Concrete in Structures - Part 1 Diagnosis (AAR 6.1). Springer Netherlands, pp. 63-64; 2013. ISBN 978-94-007-6567-2.

[19] Sahu, S. and Thaulow, N. Delayed ettringite formation in Swedish concrete railroad ties. Cement and Concrete Research, 34, 1675-1681; 2004. DOI: 10.1016/j.cemconres.2004.01.027

[20] Escadeillas, G., Aubert, J-E., Segerer, M., Prince, W. Some factors affecting delayed ettringite formation in heat-cured mortars. Cement and Concrete Research, 37 (10), 14451452; 2007. DOI: 10.1016/j.cemconres.2007.07.004.

[21] Scrivener, K. L., Taylor, H. F. W. Delayed ettringite formation: a microstructural and microanalytical analysis. Adv. Cem. Res., 5 (20), 139-146; 1993. DOI: 10.1016/09589465(96)00017-0. 
[22] Diamond, S. Delayed ettringite formation - Processes and problems. Cem. Concr. Comp., 18, 205-215; 1996. DOI: 10.1016/0958-9465(96)00017-0.

[23] Taylor, H. F. W., Famy, C., Scrivener, K. L., Delayed ettringite formation. Cem. Concr. Res., 31 (5), 683-693; 2001. DOI: 10.1016/S0008-8846(01)00466-5.

[24] Paul, M., Glasser, F. P. Impact of prolonged warm $\left(85^{\circ} \mathrm{C}\right)$ moist cure on Portland cement paste. Cement and Concrete Research, 30, 1869-1877; 2000. 10.1016/S00088846(00)00286-6.

[25] Pardo-Bosch, F., Campos, A., López, C.M., Aguado, A. Fisuras estructurales en presas de hormigón con expansiones: enseñanzas prácticas. V Congreso ACHE, 25-27 October, Barcelona (Spain), p.245-254; 2011. 